\title{
Software firm falls victim to shifting bioinformatics needs
}

\section{Jonathan Knight, Oakland}

DoubleTwist, once one of the most dynamic bioinformatics companies of the dotcom age, died quietly on 7 March at its home in Oakland, California.

At its peak, the software firm beat both public and private DNA sequencers to a count of the genes in the human genome. But its death, after a prolonged decline, was barely noticed outside the world of bioinformatics.

DoubleTwist was born as Pangea Systems in 1993, when Joel Bellenson and Dexter Smith, graduates of Stanford University in the heart of California's Silicon Valley, decided that a market was developing for computer software to manage the explosion of data being produced by geneticists.

Four years later they came up with a business plan that attracted the interest of the valley's top venture-capital firms. By the end of 1997, Pangea had \$7.5 million in the bank and a new chief executive, John Couch.

Couch was a former employee of Apple Computer, and his vision for Pangea Systems, he said at the time, was inspired by Apple's model of user-friendliness. Pangea's mission was to develop tools that would make genome analysis easy for biologists who had better things to do than program computers.

Some Pangea Systems software sold quite well, but the company was up against a stream of free genome-analysis tools flowing out of academic institutions where student programmers had begun doing thesis work in biology labs. So in December 1999, the company reinvented itself as DoubleTwist.

DoubleTwist.com was Pangea's new web portal, which allowed anyone with a browser to probe the public genome data. According to old Pangea press releases, it was originally intended to be free, to showcase the company's genome-crunching ability. But when it became DoubleTwist, the company moved the portal to the core of its business, charging up to $\$ 10,000$ a year for subscriptions.

At the same time, the company was secretly collaborating with Sun Microsystems, a computer company based in Palo Alto, California, to scour the public humangenome database for genes. On 8 May 2000, less than two months before the announcement at the White House of plans to publish the results of the public and private sequencing endeavours, DoubleTwist made headlines by announcing that it had discovered 105,000 genes in the genome.

Joseph Alper, who used to work for DoubleTwist, remembers it as an exuberant time. The company, for example, took its 200 employees on an outing to a horse race meeting. "It was typical of the dotcom attitude before the bubble burst," he says.

In September 2000, the company registered for a public offering on the stock market, but withdrew the offering a few months later, having missed the market's high point. Despite a few software deals, DoubleTwist

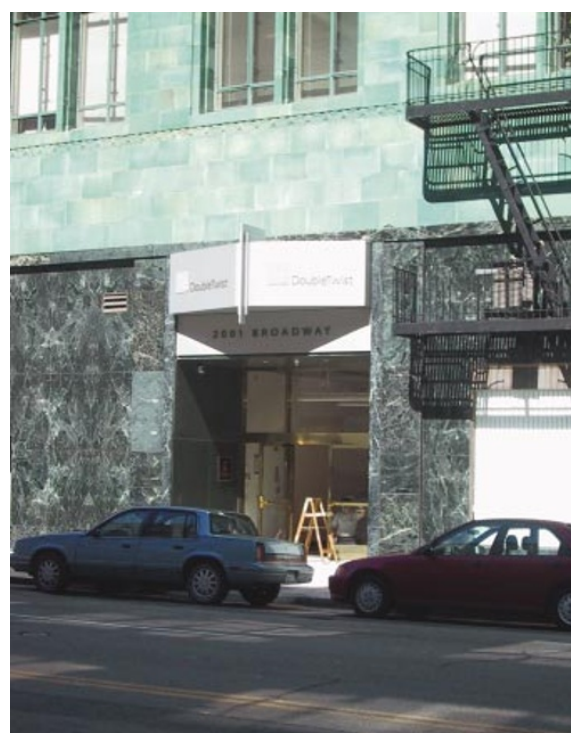

Final twist: the shutters are up at a company that sought to gain from repackaging genomic data.

never obtained the income it needed to survive. By January, its staff had been cut to 60 .

"Most genome informatics is done inhouse, in both industry and academia," says Sean Eddy, who writes gene-hunting programs at Washington University in St Louis, Missouri. Incyte Genomics, of Palo Alto, and Celera, the most famous of the genome information companies, have both seen the writing on the wall, and have sought to recast themselves as drug-discovery firms.

These changes have shaken investors, but the bioinformatics business is not dead, says Stephen Lincoln of InforMax, a biotech software firm based in Bethesda, Maryland. "Clearly we are going through a shakeout phase right now," he says.

\section{Baiting plan to remove fox threat to Tasmanian wildlife}

\section{Carina Dennis, Sydney}

The deliberate introduction of foxes into Tasmania, the island off the southern coast of the Australian mainland, is threatening to devastate the island's unique ecology, wildlife biologists say.

At a conference in the Tasmanian city of Launceston earlier this month, fox and pestcontrol experts called for steps to eradicate the foxes before the breeding season begins in July. Unless action is taken before then, they say, the island's fox problem could get out of control.

Tasmania is the last refuge for a long list of species that have been wiped out in mainland Australia. Many of these are vulnerable to predation by foxes.

"The information that the authorities have received leaves no doubt that foxes were deliberately brought into Tasmania," says Nick Mooney, a member of the state government's fox task force, which was set up last year when the problem was first identified. It is believed that the foxes were deliberately imported, perhaps by individuals who wanted new game to hunt or who were angered by the recent introduction of stricter gun-control laws. A police investigation is under way.

There are estimated to be at least a dozen foxes in the state, says Tony Peacock, chief executive of Australia's Pest Animal Control Cooperative Research Centre. "Unless action is taken to eradicate the foxes before the breeding season starts, the battle to keep Tasmania fox-free may be lost," says Peacock, who says that an estimated 77 native species could be in jeopardy as a result.

Farmers, biologists and conservationists at the Launceston meeting agreed that the foxes should be eliminated by baiting them with sodium monofluroacetate - a poison better known to farmers as ' 1080 ' — in conjunction with shooting and trapping. Use of the bait is highly controversial in Tasmania, where conservationists object to farmers and foresters using it to control populations of native animals, such as opossums and wallabies, which graze on crops and tree seedlings. Biologists and wildlife managers are trying to work out how to present the bait in a form that will be accessible to foxes, but not to other native carnivores, which include marsupial species such as quolls and the Tasmanian devil.

Closer to breeding time, Roger Short, an expert in reproductive biology at the University of Melbourne, hopes to test the use of sterilized vixens carrying oestrogen implants - which keep them in constant oestrus or 'heat' - to lure male foxes, which will then be killed. 